\title{
Gastric band migration following laparoscopic adjustable gastric banding (LAGB): two cases of endoscopic management using a gastric band cutter
}

\author{
Pawel Rogalski ${ }^{1}$, Hady Razak Hady², Andrzej Baniukiewicz', Andrzej Dąbrowski ${ }^{1}$, Fabian Kaminski², Jacek Dadan² \\ 1Department of Gastroenterology and Internal Medicine, Medical University of Bialystok, Poland \\ $21^{\text {st }}$ Department of General and Endocrinological Surgery, Medical University of Bialystok, Poland
}

Videosurgery and Other Miniinvasive Techniques 2012; 7 (2): 114-117 DOI: $10.5114 /$ wiitm.2011.25983

\begin{abstract}
Laparoscopic adjustable gastric banding (LAGB) is one of the most frequently used minimally invasive and reversible procedures for the treatment of morbid obesity. Migration of the gastric band into the gastric lumen is a rare late complication of LAGB. Previous attempts at endoscopic removal of migrated bands have included the use of endoscopic scissors, laser ablation and argon plasma coagulation (APC). We report two cases of successful endoscopic management of gastric band migration using a gastric band cutter.
\end{abstract}

Key words: band, cutter, laparoscopic adjustable gastric banding, migration.

\section{Introduction}

Laparoscopic adjustable gastric banding (LAGB) is one of the most frequently used minimally invasive and reversible procedures for the treatment of morbid obesity [1, 2].The LAGB operation requires application of a silicon band containing an elastic balloon, that can be regulated by a port located subcutaneously, enabling injection and extraction of fluid. The band is applied around the upper part of the stomach and in this way two reservoirs are created a smaller, superior one of $20 \mathrm{ml}$ volume, and a significantly larger, inferior one [3, 4].

The main complications associated with LAGB include gastric perforation, migration of the band into the gastric lumen and band displacement, with resultant pouch enlargement [5]. Band migration is a long-term complication of unclear mechanism. Suggested aetiological factors of this complication are rejection reaction against the silicon band, external pressure applied to the gastric wall by an overfilled band, and internal pressure applied as a result of ingestion of excessively large food boluses [6]. Previous attempts at endoscopic removal of migrated bands have included the use of endoscopic scissors, laser ablation and argon plasma coagulation (APC) $[7,8]$.

\section{Case reports}

\section{Case 1}

A 47-year-old woman with morbid obesity (body mass index [BMI] $45 \mathrm{~kg} / \mathrm{m}^{2}$ ) underwent LAGB (gastric band manufacturer - Johnson\&Johnson $\left.{ }^{\circledR}\right) 3$ years earlier and had effectively lost $18.5 \%$ of weight (BMI reduction of $8.02 \mathrm{~kg} / \mathrm{m}^{2}$ ). The band filling was maximally $8 \mathrm{ml}$. The weight gain of $14.9 \%$ (BMI gain of $5.25 \mathrm{~kg} / \mathrm{m}^{2}$ ) was observed 2 years after LAGB. Gastroscopy revealed almost total migration of the band 
into the gastric lumen and there was a tissue bridge that held the band to the gastric wall (Figure 1).

The port system was removed surgically with the patient under local anaesthesia. The connecting tube was cut and the rest of the tube was left inside the peritoneal cavity. It was pulled with forceps into the gastric lumen during endoscopy a few weeks later (Figure 2). Endoscopic extraction of the band was performed with surgical standby a few months after removal of the port system. The band was cut using an A.M.I. ${ }^{\circledR}$ Aigner Gastric Band Cutter and extracted with forceps (Figures 3, 4). There were no complications of the procedure and the patient was discharged the next day.

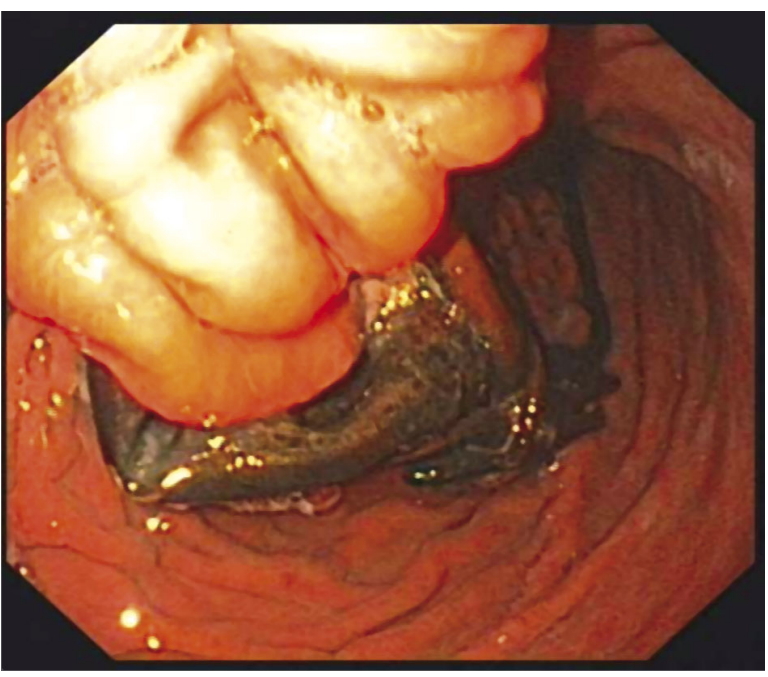

Figure 1. Endoscopic view of migrated gastric band (patient 1)

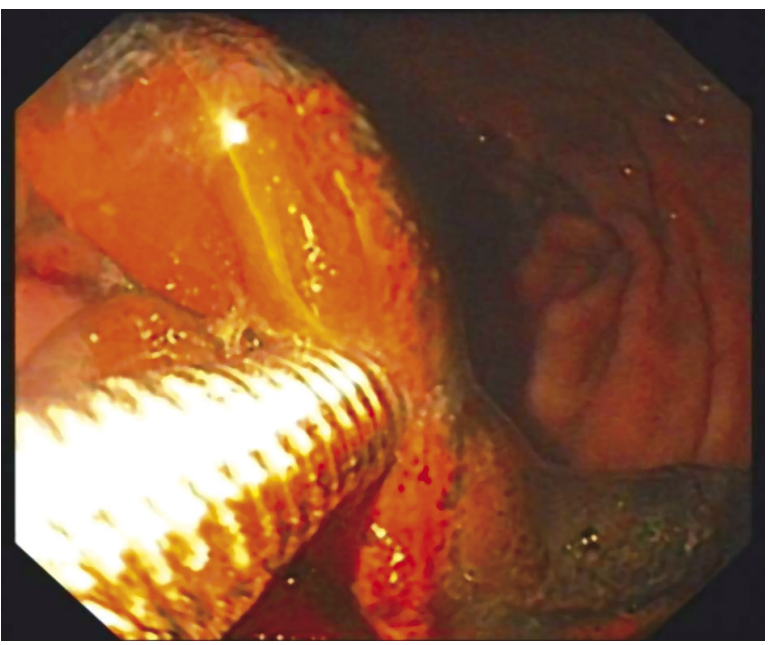

Figure 3. Cutting of the gastric band using the gastric band cutter (patient 1)

\section{Case 2}

A 34-year-old man with morbid obesity (body mass index $50 \mathrm{~kg} / \mathrm{m}^{2}$ ) underwent LAGB (gastric band manufacturer - A.M.I. $\left.{ }^{\circledR}\right) 5$ years earlier and had successfully lost $20.68 \%$ of weight (BMI reduction of $9.54 \mathrm{~kg} / \mathrm{m}^{2}$ ). The maximal band filling was $8 \mathrm{ml}$. Weight gain of $13.04 \%$ (BMI gain of $5.05 \mathrm{~kg} / \mathrm{m}^{2}$ ) was observed during the last 6 months. There were no other symptoms. Gastroscopy and abdomen computed tomography (CT) imaging revealed almost total migration of the band into the gastric lumen (Figures 5,6$)$. The port system was removed surgically with the patient under local anaesthesia. The connec-

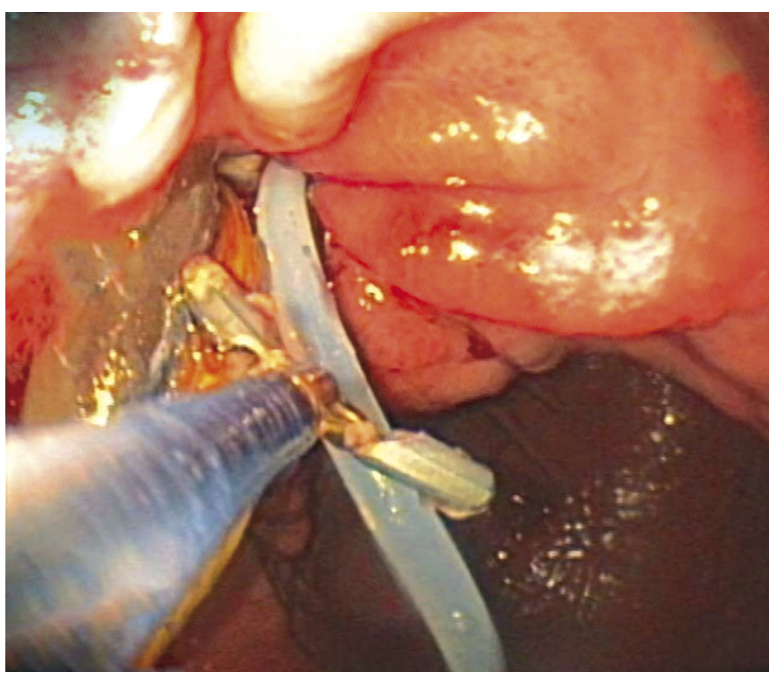

Figure 2. Pulling of the connecting tube into the gastric lumen with forceps (patient 1)

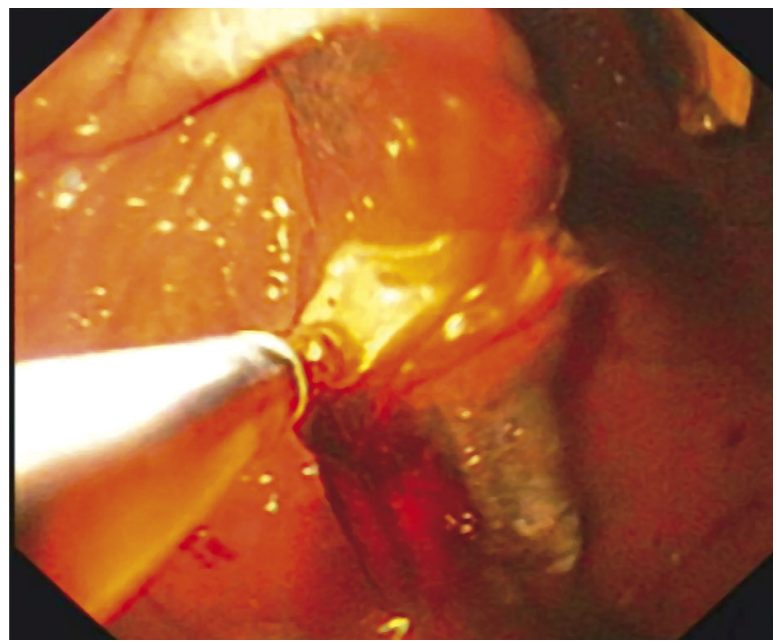

Figure 4. Extraction of the gastric band with forceps (patient 1) 


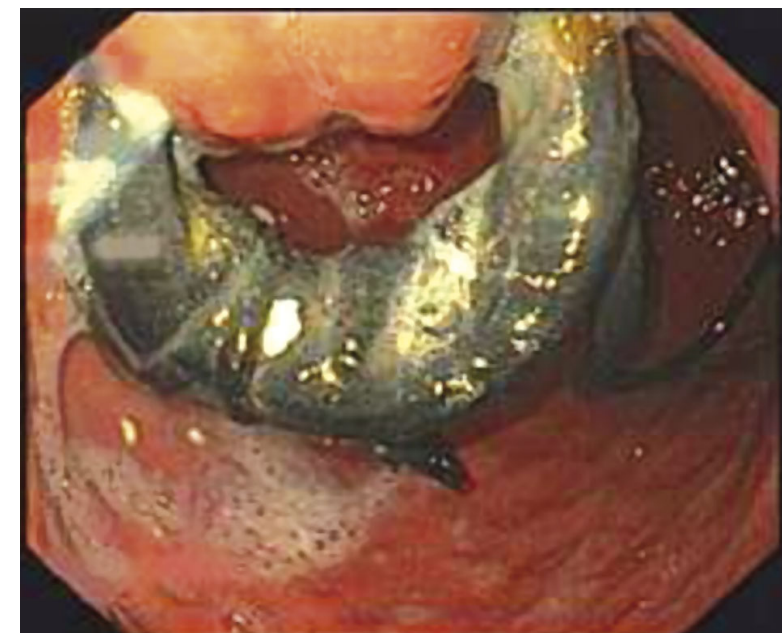

Figure 5. Endoscopic view of migrated gastric band (patient 2)

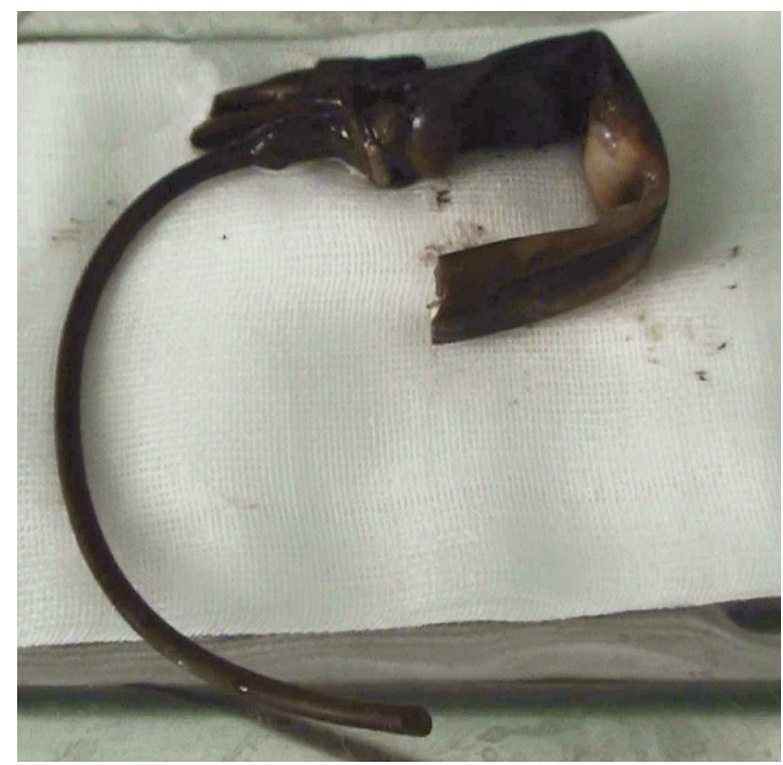

Figure 7. The gastric band after successful endoscopic extraction from the stomach

ting tube was cut and the rest of the tube was left inside the peritoneal cavity. It slipped spontaneously into the stomach during the next 6 months. Endoscopic extraction of the band was performed with surgical standby a few months after removal of the port system. The band was cut using an A.M.I. ${ }^{\circledR}$ Aigner Gastric Band Cutter and extracted with a polypectomy snare (Figure 7). There were no complications of the procedure. The patient was discharged the next day.

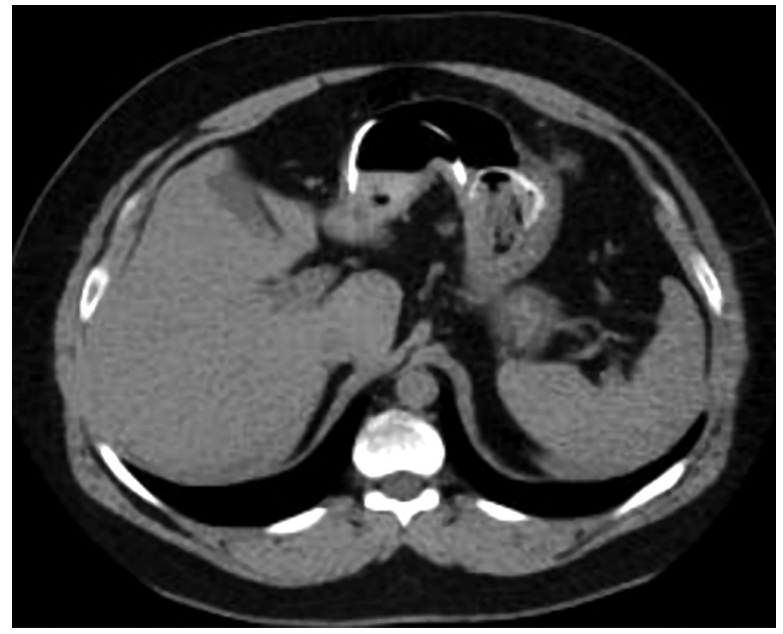

Figure 6. Computed tomography scan showing migrated gastric band with connection tube inside the stomach (patient 2)

\section{Discussion}

Between May 2005 and December 2010, 105 consecutive patients had an adjustable gastric band implanted in our institution. Intragastric band migration occurred in 2 patients (1.9\%).

Migration of the gastric band into the gastric lumen is a rare late complication of LAGB. The main symptoms suggesting gastric band migration are weight gain and epigastric pain. Migrated gastric bands should be retrieved from the stomach to preclude obstruction. The risk of gastric perforation after an endoscopic procedure is higher in patients with partial penetration of the gastric band. Thus, in patients who are asymptomatic, according to the available literature data and our experience we suggest waiting for almost complete migration and endoscopic removal of the penetrated gastric band after previous surgical extraction of the port system [6].

\section{References}

1. Bobowicz M, Michalik M, Orłowski M, Frask A. Bariatric single incision laparoscopic surgery - review of initial experience. Videosurgery and Other Miniinvasive Techniques 2011; 6: 48-52. 2. Kirshtein B, Lantsberg L, Mizrahi S, Avinoach E. Bariatric emergencies for non-bariatric surgeons: complications of laparoscopic gastric banding. Obes Surg 2010; 20: 1468-78.

3. Dadan J, Iwacewicz P, Razak Hady H. Quality of life evaluation after selected bariatric procedures using the Bariatric Analysis and Reporting Outcome System. Videosurgery and Other Miniinvasive Techniques 2010; 5: 93-9. 
4. Stanowski E, Paśnik K. Bariatric surgery - the current state of knowledge. Videosurgery and Other Miniinvasive Techniques 2008; 3: 71-86.

5. Blanco Engert R, Gascon M, Weiner R, et al. Video-laparoscopic placement of adjustable gastric banding in the treatment of morbid obesity. Preliminary results after 407 interventions. Gastroenterol Hepatol 2001; 24: 381-6.

6. Baldinger R, Mluench R, Steffen R, et al. Conservative management of intragastric migration of Swedish adjustable gastric band by endoscopic retrieval. Gastrointest Endosc 2001; 53: 98-101.

7. Lunde OC. Endoscopic laser therapy for band penetration of the gastric wall after gastric banding for morbid obesity. Endoscopy 1991; 23: 100-1.

8. Meyenberger C, Gubler C, Hengstler PM. Endoscopic management of a penetrated gastric band. Gastrointest Endosc 2004; 60: 480-1. 